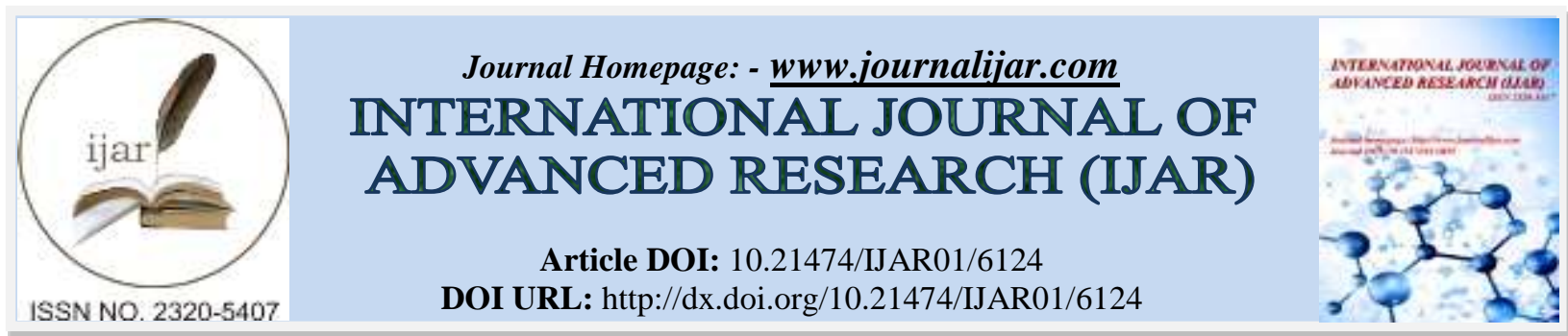

RESEARCH ARTICLE

\title{
DISQUIETING EFFECT OF ZNS NANOPARTICLES ON AN INDIAN MINOR CARP, LABEO BATA (HAMILTON, 1822) AND THE ASIAN DWARF STRIPED CATFISH MYSTUS VITTATUS (BLOCH, 1794) WITH RESPECT TO SOME OF THEIR VITAL ORGANS: A COMPARATIVE STUDY.
}

Nilanjana Chatterjee ${ }^{1}$ and ${ }^{*}$ Baibaswata Bhattacharjee ${ }^{2}$

Department of Zoology, Ramananda College, Bishnupur-722122, Bankura, India.

2. Department of Physics, Ramananda College, Bishnupur-722122, Bankura, India.

\section{Manuscript Info}

Manuscript History

Received: 21 October 2017

Final Accepted: 23 November 2017

Published: December 2017

Keywords:-

ZnS nanoparticles; Photo-oxidation; Hypoxia; Growth; Labeo bata; Mystus vittatus.

\section{Abstract}

Enhanced surface photo-oxidation property associated with $\mathrm{ZnS}$ in its nanoparticle form induced alterations in the physico-chemical properties of water in a dose dependent manner. Exposure of $\mathrm{ZnS}$ nanoparticles in water resulted in depletion of dissolved oxygen content and reduction in $\mathrm{pH}$ value of water significantly. This observation was more prominent for $\mathrm{ZnS}$ nanoparticles with smaller sizes.

When exposed to ZnS nanoparticles, both the fish species Labeo bata and Mystus vittatus, responded to hypoxia with varied behavioural, physiological and cellular responses in order to maintain homeostasis and organ function in an oxygen-depleted environment. Due to the minimization of food uptake, the hepatic cells of both the fish were found to shrink and empty spaces generated in between them as they used storage deposit to maintain the metabolic activity of the fish. However, the change in hepatic tissue layout was more noteworthy in case of L. bata.

The kidneys of both the exposed fish species showed shrinkage of glomerulus and dilution of tubular lumen due to reduction in glomerular filtration rate in oxygen depleted atmosphere. Vacuolization and hyaline degeneration of tubular epithelium were also seen in the renal histomorphology of both the fish when the exposure time exceeded 6 days. Again in this case, the alterations in renal histomorphology were more rapid and distinguishable in case of $L$. bata.

Both the fish species showed prominent alterations in their gill histomorphology displaying dissociation of gill epithelium layer, lamellae fusion, lamellae curling, angiogenesis, vasodilation and disruption of filament and lamellae when they face dose dependent $\mathrm{ZnS}$ nanoparticle induced hypoxia and environmental acidification in their habitat. The size and dose dependent changes in gill tissue layout were noticed to be more severe in the case of $L$. bata compared to $M$. vittatus.

These observations suggest that the species L. bata is more vulnerable compared to the species $M$. vittatus against $\mathrm{ZnS}$ nanoparticle exposure when vital organs like liver, kidney and gills are concerned. 


\section{Introduction:-}

Ballooning of nanotechnology and escalating uses of nanoparticles in varied fields of sciences [1-3] have increased considerably the probability that the nanoparticles would end up in water courses either as chemical, medical, industrial or domestic wastes. ZnS nanoparticles (NPs) are one of such materials that can be found in the wastes of cosmetic, pharmaceutical and rubber industries. Apart from the various physiological disorders due to direct uptake of nanoparticles by the aquatic animals through different parts of their body [4-10], ZnS NPs are expected to exhibit some passive effects on aquatic environment by changing important physicochemical parameters of water owing to its property of surface photo-oxidation [11]. As a result of enhanced surface photo-oxidation property of $\mathrm{ZnS}$ in its nanoparticle form, the dissolved oxygen content and $\mathrm{pH}$ value of water are found to reduce in a dose dependent manner from their normal values, when $\mathrm{ZnS}$ NPs of different sizes are exposed to the water in various concentrations for different times of exposure [8, 11- 12]. This property is more prominent for ZnS NPs with smaller sizes. Consequently under the exposure of $\mathrm{ZnS}$ NPs, the aquatic fauna of that particular habitat are forced to live in an oxygen depleted and acidified atmosphere [8, 11-12]. Fish respond to hypoxia and environmental acidification with varied behavioural, physiological, and cellular responses in order to maintain homeostasis and organ function in a hostile atmosphere [13-19] resulting in abnormal growth and maturity in Mystus vittatus [11,12, 20, 21] and showing adverse effect on different organs of Labio bata [22], Mystus vittatus [11] and Mystus tengara [23, 24].

An identical experimental exposure of same kind of nanoparticles may produce diverse effect on different fish species depending upon their inherent ability of acclimatization against the hostile conditions. In the present study, two economically important teleosts that belong to two different phylogenetic groups have been selected to monitor and to be compared when exposed to ZnS NPs. The freshwater Indian minor carp Labeo bata is a cypriniformes and is known to be susceptible against harsh atmospheric conditions. The Asian striped catfish Mystus vittatus is a siluriformes and in spite of lacking additional accessory respiratory organs, it is relatively sturdier to fight against any atmospheric change. Moreover both the species have high nutritional values and are very popular among fish lovers. These make both the species economically important in international fish market and consequently attractive contenders for aquaculture in the south-east Asia. Therefore, the changing behaviour in growth and maturity of these fish species due to exposure of $\mathrm{ZnS}$ NPs may also have its detrimental effect on the commercial fish market.

Therefore, the aim of our present study is to monitor systematically and compare the adverse effect of ZnS NPs on $L$. bata and $M$. vittatus with respect to some of their vital organs, viz. liver, kidney and gills. This study will also help to realise how the growth and maturity of fish are being hampered when exposed to ZnS NPs.

\section{Experimental:-}

\section{Preparation and Characterization of ZnS Nanoparticles}

The $\mathrm{ZnS}$ NPs are prepared by simple wet chemical method using zinc nitrate hexahydrate $\left[\mathrm{Zn}\left(\mathrm{NO}_{3}\right)_{2} \cdot 6 \mathrm{H}_{2} \mathrm{O}\right]$ as $\mathrm{zinc}$ precursor and sodium sulphide $\left(\mathrm{Na}_{2} \mathrm{~S}\right)$ as sulphur precursor [12, 25].The as precipitated nanoparticles were filtered out and were washed for several times in distilled water and absolute alcohol (100\% ethanol) and then were dried at $30 \circ \mathrm{C}$ in a vacuum oven. The nanoparticles were characterized using X-ray diffraction study (XRD), Transmission Electron Microscopy (TEM), Particle Size Analysis (PSA), Energy dispersive X-ray study (EDX), and X-ray Photoelectron Spectroscopy (XPS). The synthesis process and characterization results have been discussed in detail elsewhere $[12,25]$.

\section{Measurement of dissolved oxygen content and pH value of water}

Properly calibrated electronic lab meters with probes having accuracy up to one decimal point were used to measure the dissolved oxygen content and $\mathrm{pH}$ of water. A calibration curve was drawn and used to obtain the dissolved oxygen content in water under different experimental conditions.

\section{Fish Husbandry}

Matured live L. bata and M. vittatus of both sex groups were collected from local fishermen. After collection, fish were kept in water tight containers (capacity of 100 litres) containing tap water that has been allowed to stand for a few days. Fish are maintained at $25^{\circ}-30^{\circ} \mathrm{C}$ of temperature to ensure the natural environment. Small, regular supplies of food were provided to the fish. 


\section{Toxicity test}

Both the fish species were exposed to five concentrations $(100,250,500,750$ and 1,000 $\mu \mathrm{g} / \mathrm{L})$ of the $\mathrm{ZnS}$ NPs of different sizes $(3,7,12$ and $20 \mathrm{~nm})$ for different times of exposure $(6,12,18$ and 24 days) to discern the disquieting effects on liver, kidney and gills of the fish.

\section{Histological and histometric study:-}

After the controlled and treated fish were sacrificed; the liver, kidney and gills were dissected out and subjected to routine histological procedures. Upgrading or dehydration of hepatic, renal and branchial tissues was done by putting them for 10 minutes each ( 2 changes) in distilled water, 30\%, 50\%, 70\%, and 90\% ethanol, and finally absolute alcohol (100\% ethanol). Dehydration using upgraded alcohol was followed by xylene treatment, paraffin embedding (melting point $56^{\circ}-58^{\circ}$ Celsius), section cutting $(4 \mu \mathrm{m})$, and staining using Delafield's Haematoxylin and Eosin (HE) before they were observed under a compound light microscope at different desired magnifications (X 400, X 600, X 800) and photographed with a digital camera.

For histometric analysis, hepatocyte and glomelular diameters were measured with reticulomicrometer and ocularmicrometer attached to the compound light microscope. Each measurement was made four times and their mean value was used for any analysis.

\section{Statistical analysis and curve fitting:-}

All data were expressed as means \pm SE. One-way analysis of variance was run to compare the differences between groups treated under different experimental conditions and control groups. Differences were considered statistically significant when $\mathrm{p}<0.05$. Curve fitting to the experimentally obtained data was done using the software Origin 9.

\section{Results and discussions:-}

\section{ZnS NP induced hypoxia and environmental acidification}

In the present study, the dissolved oxygen content in water $\left(\mathrm{DO}_{2}\right)$ was measured to be $8.9 \mathrm{mg} / \mathrm{L}$ at $15^{\circ} \mathrm{C} \mathrm{before} \mathrm{any}$ nanoparticle was introduced in it. This value was found to decrease both with increasing nanoparticle concentration as well as nanoparticle exposure time in water at the same temperature. The value of dissolved oxygen content in water reached to as low as $2.9 \mathrm{mg} / \mathrm{L}$ for nanoparticles of size $3 \mathrm{~nm}$ at a concentration of $1000 \mu \mathrm{g} / \mathrm{L}$ and exposure time of 6 days.

The photo-oxidation of the surface of $\mathrm{ZnS}$ NPs using the dissolved oxygen of water under sunlight and consequent reduction of dissolved oxygen content in water has been confirmed from detailed study of $\mathrm{S} 2 \mathrm{p}$ core level X ray photoelectron spectra of $\mathrm{ZnS}$ nanoparticles after different time of exposures [12]. During the surface photo-oxidation process of $\mathrm{ZnS}$ NPs, The $\mathrm{S}$ atoms exposed to the $\mathrm{ZnS}$ surface got oxidized and an increase in concentration of chemisorbed $\mathrm{SO}_{2}$ at $\mathrm{ZnS}$ surface with increasing exposure time was observed in the samples [12]. The oxide leaves the surface as a molecular species $\left(\mathrm{SO}_{2}\right)$, leaving $\mathrm{Zn}$ and a freshly exposed layer of $\mathrm{ZnS}$ behind. Water may dissolve a part of the $\mathrm{SO}_{2}$ released in the process causing reduction in the $\mathrm{pH}$ value of the water [12, 26]. Subsequently under the exposure of ZnS NPs, the aquatic fauna of that particular habitat were forced to live in an oxygen depleted and acidified atmosphere $[11,12,20-26]$.

In the present study, the $\mathrm{pH}$ value of water was found to decrease when exposed to ZnS NPs in a dose dependent manner for a fixed exposure time of 6 days. In controlled condition the $\mathrm{pH}$ value of the water used in this experiment was measured to be 7.6. This value was found to decrease both with increasing nanoparticle concentration as well as nanoparticle exposure time in water for a fixed nanoparticle size. The rate of reduction in $\mathrm{pH}$ value was found to be higher for the nanoparticles with smaller sizes. In our experiment, the $\mathrm{pH}$ value of water dwindled down to 4.8 for nanoparticle concentration $(\sigma)$ of $1000 \mu \mathrm{g} / \mathrm{L}$ with size (d) $3 \mathrm{~nm}$ and exposure time (t) of 6 days. Reduction of water $\mathrm{pH}$ and consequent acidification of the environment finally lead the fishes to metabolic acidosis.

\section{Impact of ZnS nanoparticle exposure on hepatic histology}

The liver cell structure of teleosts responds very sensitively to environmental changes, e.g. in temperature, season, feeding conditions or presence of various chemicals in the water [27]. Therefore, liver histology can be used as an indicator to show the harmful effect of $\mathrm{ZnS}$ nanoparticles on L. bata and M. vittatus. Figures 1a, 2a show the histomorphology of $L$. bata and $M$. vittatus liver respectively in controlled condition portraying the liver cells in normal and healthy states. In these figures, liver cells are found to be large with regular outlines and dominated by 
storage deposits. The nuclei are found to be large and centrally located indicating the normal condition of the cells. The cells are found to be in close contact, almost no empty space is found between the cells. For exposure to $\mathrm{ZnS}$ concentration of $100 \mu \mathrm{g} / \mathrm{L}$ (Figure $1 \mathrm{~b}, 2 \mathrm{~b}$ ), few cells are found to be in degenerating states without a prominent nucleus and having diffused cytoplasmic contents. For higher concentration of $\mathrm{ZnS}$ nanoparticles $(\sigma=500 \mu \mathrm{g} / \mathrm{L})$, decrease in cell sizes due to drastic loss of storage deposits is observed (Figure 1c, 2c). Therefore, relative share of nucleus in cell volume is strongly increased. The cells are found to be in increasing isolated states having no close contact between them (Figure 1c, 1d; 2c, 2d). Under high concentration exposure of smaller ZnS nanoparticles, some of the livers also show disruption of hepatic cell cords and apoptotic changes such as chromatin condensation and pyknosis as indicated by the green arrows in figures (Figure 1d, 2d). The histological alterations are found to be
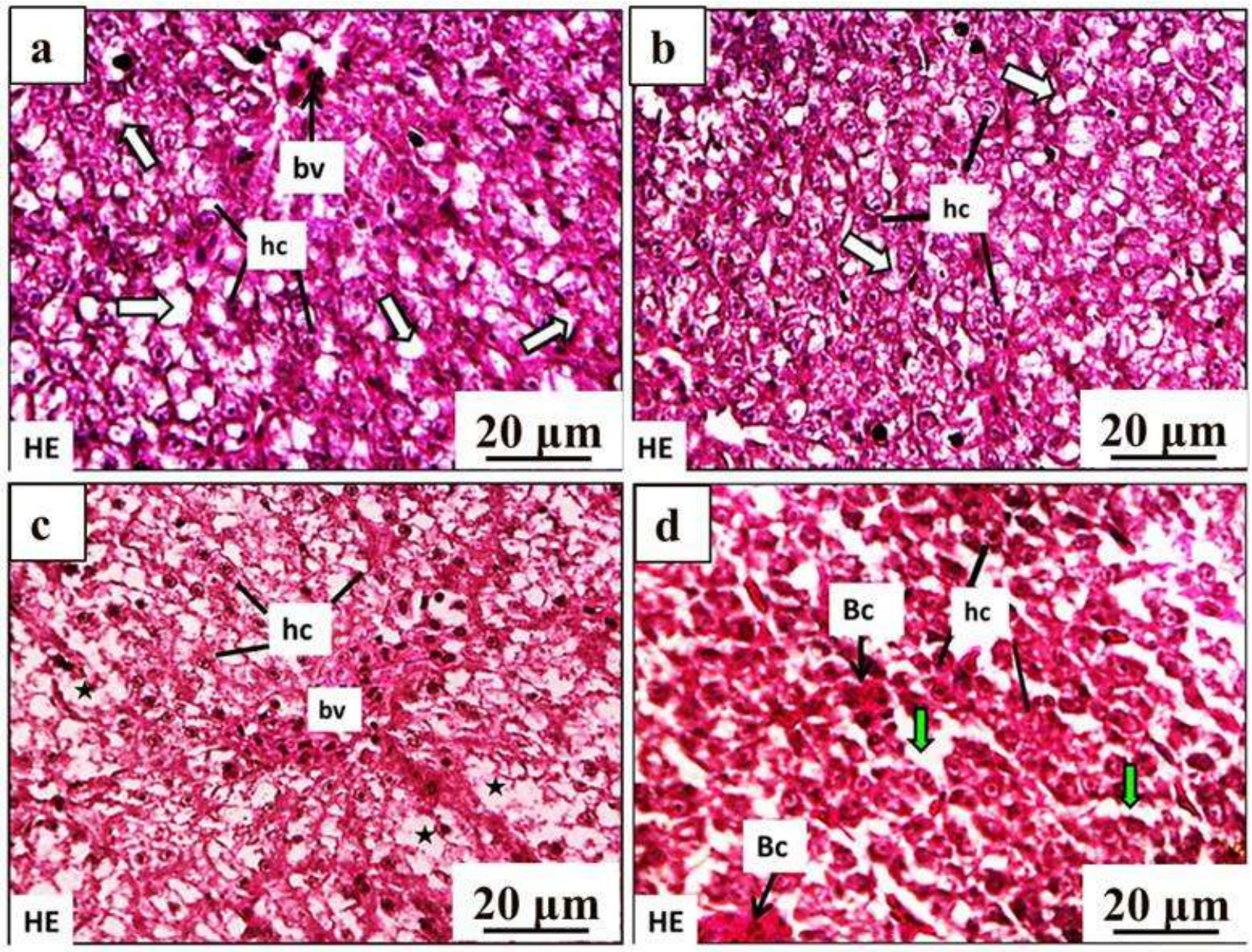

more pronounced in case of $L$. bata compared to M. vittatus.

Figure 1: Photomicrographs showing the liver histology of L. bata under (a) controlled condition, (b) exposure to $\mathrm{ZnS} \mathrm{NP}$ concentration of $\sigma=100 \mu \mathrm{g} / \mathrm{L}$ for 6 days, $\mathrm{d}=3 \mathrm{~nm}$, (c) exposure to ZnS NP concentration of $\sigma=500 \mu \mathrm{g} / \mathrm{L}$ for 6 days, $d=3 \mathrm{~nm}$ and (d) exposure to ZnS NP concentration of $\sigma=1000 \mu \mathrm{g} / \mathrm{L}$ for 6 days, $d=3 \mathrm{~nm}$. In this case, livers tissues showed disruption of hepatic cell cords and apoptotic changes such as chromatin condensation and pyknosis as indicated by green block arrows in figure. [hepatocytes (hc), fat vacuoles (fv-white block arrows), blood vessels $(\mathrm{Bv})$, empty space generated due to apoptosis $(\star)$ and blood cells $(\mathrm{Bc})]$.

These observations are indicative of degradation of liver cells under nanoparticle exposure. Due to the minimization of food intake under nanoparticle exposure, the hepatic cells of the fish are found to shrink and empty spaces generate in between them as they use the storage in the hepatocytes and fat vacuoles to maintain the metabolic activities of the fishes in this adverse condition. These effects can be associated directly with the changing feeding behavior, which in turn makes a detrimental effect on growth, maturity and spawning of the fish. Lakani et al. [28] reported reduced food intake and growth in Huso huso under hypoxia treatment. The present observation is also in agreement with previous findings that hypoxia affects both the appetite and growth rate of fish [29]. Decreased feed 
utilization might be an indicator of the higher levels of stress [30] and it could be an indirect mechanism by which prolonged hypoxia reduces growth and may be a way to reduce energy and thus oxygen demand [31].

The quantitative study on decreasing hepatocyte diameters for both fish species has been conducted to compare the adverse effect of $\mathrm{ZnS}$ NP on these fish. Figure 3 and figure 4 show the change in the values of hepatic cell diameter

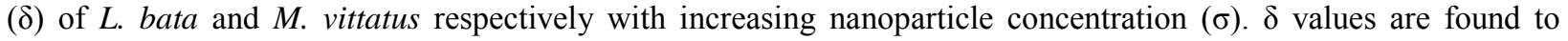
decrease with increase in $\sigma$ value up to $500 \mu \mathrm{g} / \mathrm{L}$ for every size of the nanoparticles (d) used. Beyond this concentration, this value remains nearly constant. Data for both the fish species are fitted well with first order exponential decay curves expressed by the equation

$$
\delta=\delta_{0}+\alpha e^{\frac{-\sigma}{\tau}}(1)
$$

where $\delta_{0}$ is the average hepatocyte size without any nanoparticle exposure, $\alpha$ is a parameter and inverse of $\tau$ determines the slope of the curve. Therefore smaller values of $\tau$ corresponds to the steeper curves. The curve fitting parameters under different experimental conditions are shown in the figure 3 (inset) and figure 4 (inset) for L. bata and $M$. vittatus respectively. An investigation on the slopes of the curves establishes undoubtedly that the detrimental effect is stronger for particles with smaller sizes in both the cases. From the $\tau$ values of tables it is also clear that for a fixed nanoparticle size; the detrimental effect is greater for L. bata compared to M. vittatus.
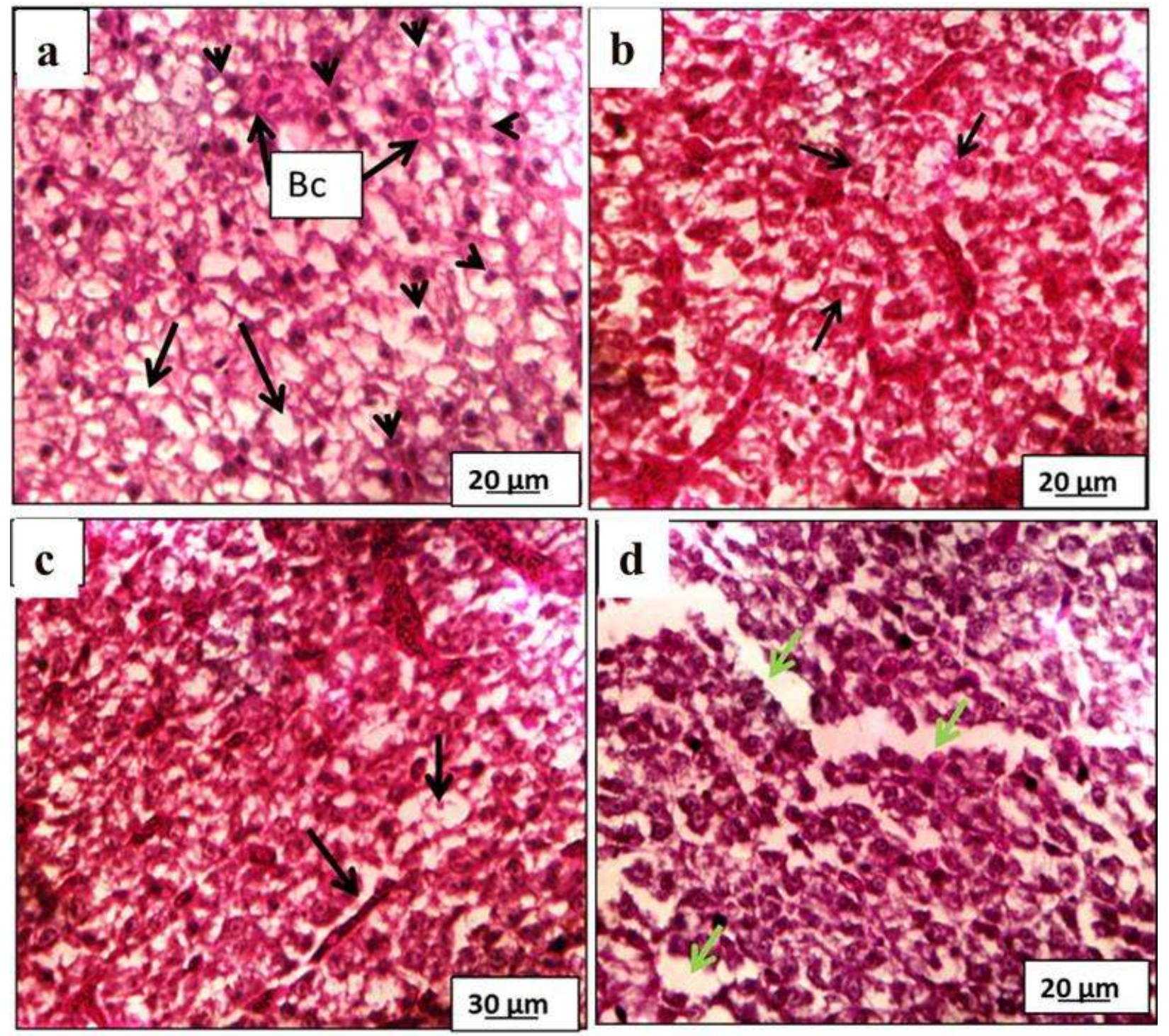

Figure 2:- Photomicrographs showing the liver histology of $M$. vittatus under (a) controlled condition, (b) exposure to $\mathrm{ZnS}$ NP concentration of $\sigma=100 \mu \mathrm{g} / \mathrm{L}$ for 6 days, $\mathrm{d}=3 \mathrm{~nm}$, (c) exposure to $\mathrm{ZnS} \mathrm{NP}$ concentration of $\sigma=500$ 
$\mu \mathrm{g} / \mathrm{L}$ for 6 days, $\mathrm{d}=3 \mathrm{~nm}$ and (d) exposure to $\mathrm{ZnS}$ NP concentration of $\sigma=1000 \mu \mathrm{g} / \mathrm{L}$ for $6 \mathrm{days}, \mathrm{d}=3 \mathrm{~nm}$. [Bc-

Blood cells, Fv- Fat vacuole]

These observations are indicative of degradation of liver cells under nanoparticle exposure. Due to the minimization of food intake under nanoparticle exposure, the hepatic cells of the fish are found to shrink and empty spaces generate in between them as they use the storage in the hepatocytes and fat vacuoles to maintain the metabolic activities of the fishes in this adverse condition. These effects can be associated directly with the changing feeding behavior, which in turn makes a detrimental effect on growth, maturity and spawning of the fish. Lakani et al. [28] reported reduced food intake and growth in Huso huso under hypoxia treatment. The present observation is also in agreement with previous findings that hypoxia affects both the appetite and growth rate of fish [29]. Decreased feed utilization might be an indicator of the higher levels of stress [30] and it could be an indirect mechanism by which prolonged hypoxia reduces growth and may be a way to reduce energy and thus oxygen demand [31].

The quantitative study on decreasing hepatocyte diameters for both fish species has been conducted to compare the adverse effect of ZnS NP on these fish. Figure 3 and figure 4 show the change in the values of hepatic cell diameter $(\delta)$ of L. bata and M. vittatus respectively with increasing nanoparticle concentration $(\sigma)$. $\delta$ values are found to decrease with increase in $\sigma$ value up to $500 \mu \mathrm{g} / \mathrm{L}$ for every size of the nanoparticles (d) used. Beyond this concentration, this value remains nearly constant. Data for both the fish species are fitted well with first order exponential decay curves expressed by the equation

$$
\delta=\delta_{0}+\alpha e^{\frac{-\sigma}{\tau}}(1)
$$

Where $\delta_{0}$ is the average hepatocyte size without any nanoparticle exposure, $\alpha$ is a parameter and inverse of $\tau$ determines the slope of the curve. Therefore smaller values of $\tau$ corresponds to the steeper curves. The curve fitting parameters under different experimental conditions are shown in the figure 3 (inset) and figure 4 (inset) for $L$. bata and $M$. vittatus respectively. An investigation on the slopes of the curves establishes undoubtedly that the detrimental effect is stronger for particles with smaller sizes in both the cases. From the $\tau$ values of tables it is also clear that for a fixed nanoparticle size; the detrimental effect is greater for L. bata compared to M. vittatus.

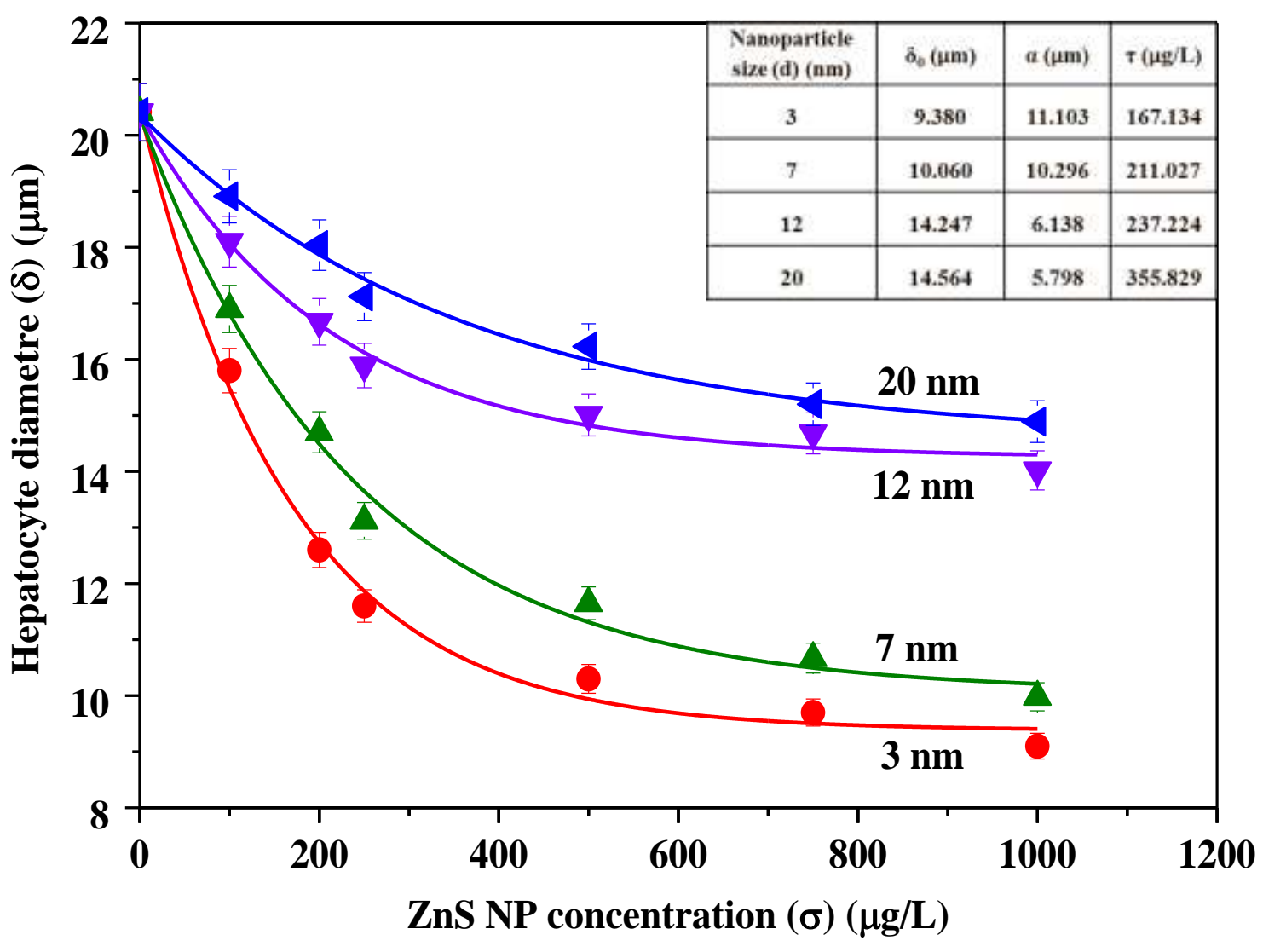


Figure 3:- Change in the values hepatic cell diameter $(\delta)$ of $L$. bata with increasing nanoparticle concentration $(\sigma)$ for exposure time (t) of 6 days along with theoretical fitted curves and fitting parameters in inset table

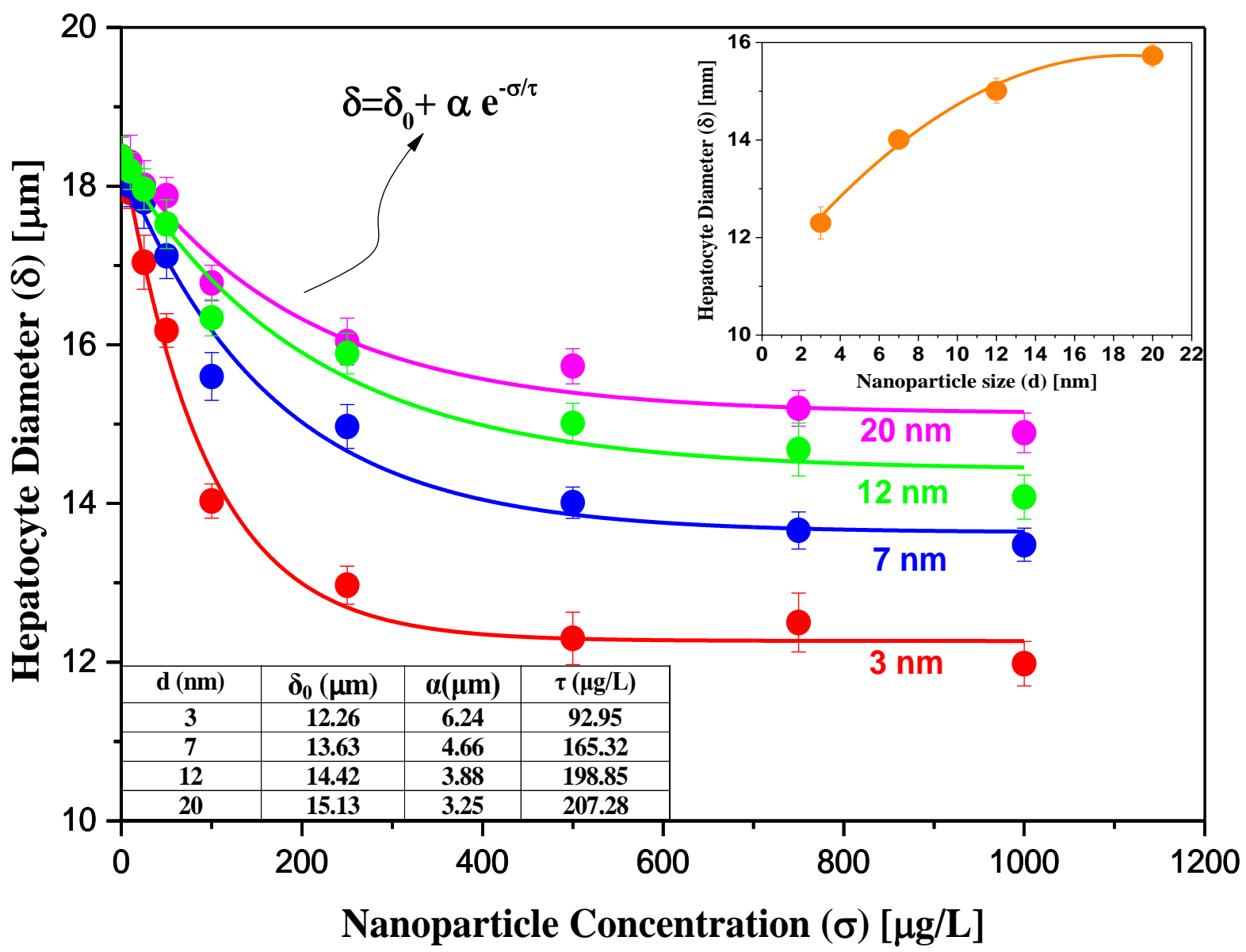

Figure 4:- Change in the values hepatic cell diameter $(\delta)$ of $M$. vittatus with increasing nanoparticle concentration $(\sigma)$ for exposure time $(t)$ of 6 days along with theoretical fitted curves and fitting parameters in inset table. Inset shows the change in $\delta$ with increasing $\mathrm{d}$ for a fixed value of $\sigma$.

\section{Impact of $\mathrm{ZnS}$ nanoparticle exposure on renal histology:}

Figures 5(a)-(d) show the renal histology of L. bata in controlled condition and under different experimental conditions while figures 6 (a)-(d) show the same for M. vittatus. The histomorphology of the controlled kidney tissues exhibit an ordinary pattern of renal corpuscles (consisting of glomerulus and Bowman's capsule) and collecting tubules with no abnormalities in any other part of the renal cellular lay out as shown in figures $3 \mathrm{a}$ and $4 \mathrm{a}$. When the fish are exposed to relatively lower concentration of ZnS NPs $(\sigma \leq 200 \mu \mathrm{g} / \mathrm{L})$, the kidneys of the fish show shrinkage in glomerulus. In addition to that, dilution of tubular lumen is also observed. For exposure to moderate value of $\mathrm{ZnS}$ NPs $(\sigma=250 \mu \mathrm{g} / \mathrm{L})$, significant decrease in glomerular size $(\mathrm{p}<0.001)$ and density $(\mathrm{p}<0.001)$ are observed in the renal tissues of the exposed fishes (Fig. 5b; 6b) compared to that of the controlled fish. For exposure to relatively higher concentration of ZnS NPs $(\sigma=500 \mu \mathrm{g} / \mathrm{L})$, significant decrease in the number density ( $\mathrm{p}<0.001)$ of collecting tubules was noticed in addition to the previous observations (Fig. 5c; 6c). Exposure to even higher concentration of ZnS NPs $(\sigma \geq 750 \mu \mathrm{g} / \mathrm{L})$, results in vacuolization in renal cell lay out and hyaline degeneration of tubular epithelium. After exposure to the highest $\mathrm{ZnS} \mathrm{NP}$ concentration $(\sigma=1000 \mu \mathrm{g} / \mathrm{L})$ used in the experiment, necrosis and dispersed inter renal cells with pyknosis of some nuclei are observed (Fig. 5d; 6d) in both $L$. Bata and M. vittatus.

Figure 7 shows the changes in the value of glomerular diameter (D) for L. bata with increasing nanoparticle concentration $(\sigma)$ for nanoparticles of different sizes (d) used, when the exposure time is fixed ( $t=6$ days). D values 
are found to decrease gradually with increase in $\sigma$ values within the experimental limit for every size of the nanoparticles (d) used and for a fixed exposure time ( $\mathrm{t}=6$ days). Similar type of qualitative variations is found in case of M. vittatus (data not shown). Strong negative correlation $(\mathrm{r}=-0.892$ for $L$. bata and $\mathrm{r}=-0.826$ for $M$. vittatus) was obtained between $\mathrm{D}$ and $\sigma$ for constant $\mathrm{d}(3 \mathrm{~nm})$ and $\mathrm{t}(6$ days). Analysis of covariance reveals significant differences between the D values $(\mathrm{p}<0.001)$ for different concentrations of nanoparticle exposures in case of both the fish species. The lumen diameter of the collecting tubules are found to decrease $(\mathrm{r}=-0.704$ for $L$. bata and $\mathrm{r}=-0.662$ for M. vittatus) and increase in muscular wall thickness $(\mathrm{r}=0.801$ for $L$. bata and $\mathrm{r}=0.752$ for M. vittatus) are observed with increasing exposure time for a fixed concentration of $\mathrm{ZnS}$ NP for both the species. Other time dependent histomorphological alterations in renal tissues is not quite prominent for relatively lower concentration of ZnS NPs $(\sigma<500 \mu \mathrm{g} / \mathrm{L})$. When the exposure time exceeds 6 days for higher concentrations $(\sigma \geq$ $500 \mu \mathrm{g} / \mathrm{L}$ ) of ZnS NPs, glomerular vacuolization and hyaline degeneration of tubular epithelium were seen in the renal histomorphology of $L$. bata. In case of M. vittatus these effects become noticeable when the exposure time exceeds 12 days.
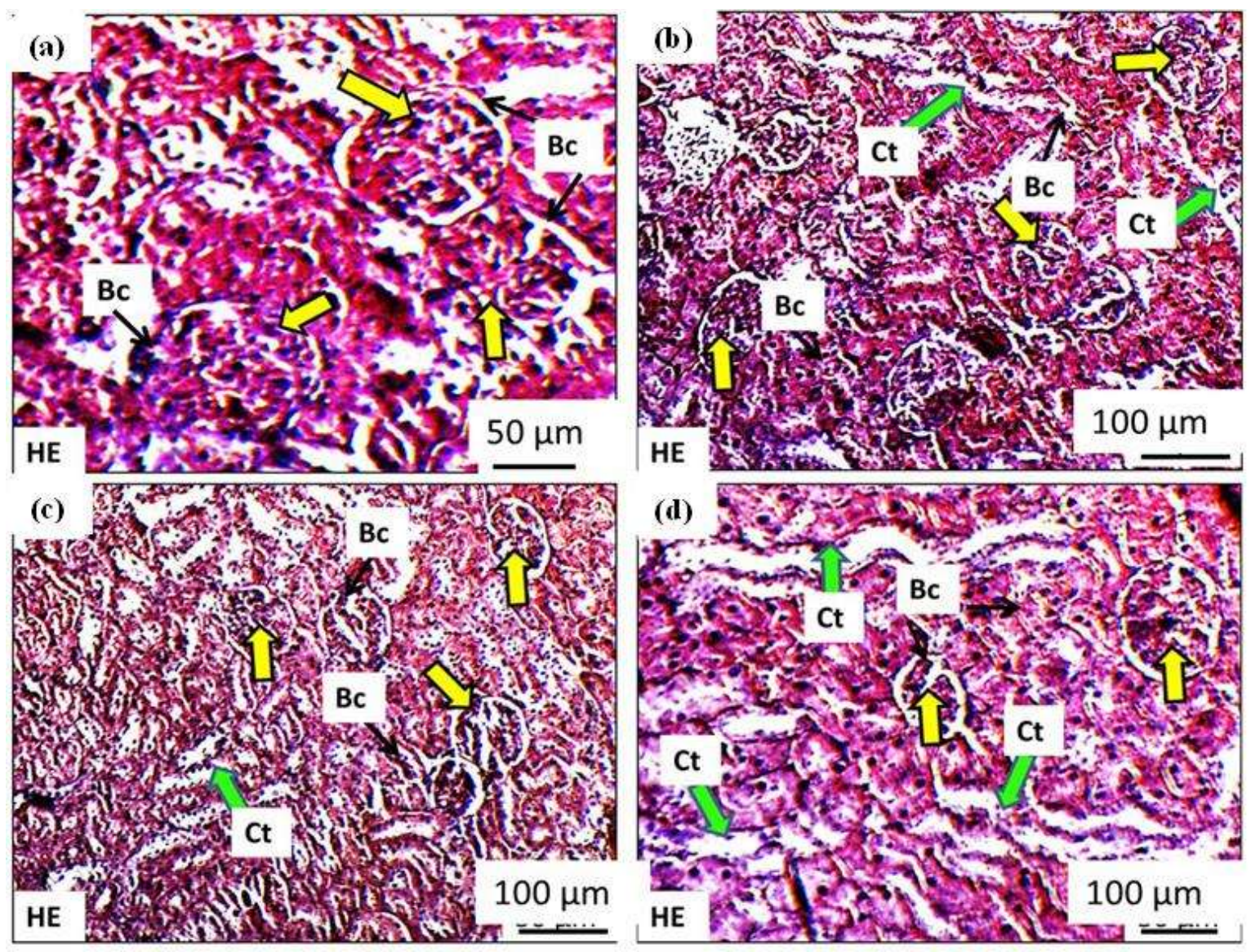

Figure 5:- Photomicrographs showing the renal histology of L. bata under (a) controlled condition, (b) for exposure to $\mathrm{ZnS} \mathrm{NP}$ concentration of $\sigma=100 \mu \mathrm{g} / \mathrm{L}$ (c) for exposure to $\mathrm{ZnS} \mathrm{NP}$ concentration of $\sigma=500 \mu \mathrm{g} / \mathrm{L}$ and (d) for exposure to $\mathrm{ZnS} N P$ concentration of $\sigma=1000 \mu \mathrm{g} / \mathrm{L}$ (in all cases $\mathrm{d}=3 \mathrm{~nm}$ and $\mathrm{t}=6$ days) [glomerulus (yellow arrow), Bowman's capsule (Bc) and collecting tubules (ct), Haematoxilin-Eosin (HE) stain]

Data of figure 7 are fitted well to the first order exponential decay curves represented by the equation

$$
D=D_{0}+A e^{\frac{-\sigma}{T}}
$$

where $\mathrm{D}_{0}, \mathrm{~A}$ and $\mathrm{T}$ are the fitting parameters as shown in table $\mathrm{I}$ for the family of curves shown in figure $4 . \mathrm{D}_{0}$ corresponded to the extrapolated value of glomerular diameter (D) if the nanoparticle concentration $(\sigma)$ reached infinity. The inverse of $\mathrm{T}$ values determined the slopes of the fitted curves. From the slope of the curves, it can be recognized indisputably that the harmful effect of ZnS NPs was sturdier for particles with smaller sizes. Inspecting 
different correlation coefficients obtained from renal histology data and comparing the $T$ values between two fish species from table I, it can be inferred undoubtedly that the alterations in renal histomorphology are more rapid in case of $L$. bata. Therefore kidneys of M. vittatus show stronger defence against $\mathrm{ZnS}$ NP induced hypoxia and environmental acidification.
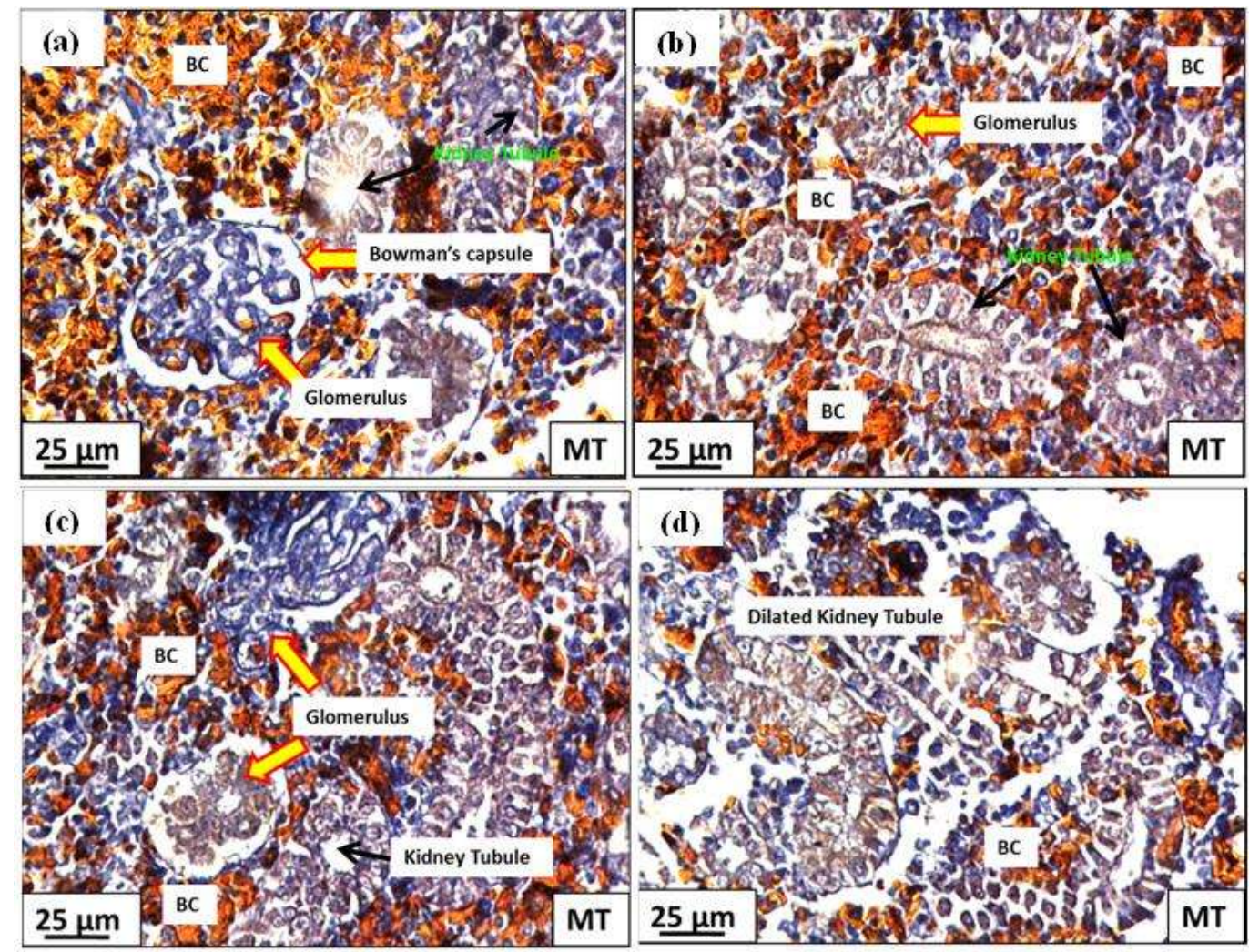

Figure 6:- Photomicrographs showing the renal histology of $M$. vittatus under (a) controlled condition, (b) for exposure to ZnS NP concentration of $\sigma=100 \mu \mathrm{g} / \mathrm{L}$, (c) for exposure to $\mathrm{ZnS} \mathrm{NP}$ concentration of $\sigma=500 \mu \mathrm{g} / \mathrm{L}$ and (d) for exposure to $\mathrm{ZnS} \mathrm{NP}$ concentration of $\sigma=1000 \mu \mathrm{g} / \mathrm{L}$ (in all cases $\mathrm{d}=3 \mathrm{~nm}$ and $\mathrm{t}=6$ days) [glomerulus (yellow arrow), Bowman's capsule (Bc) and collecting tubules (ct), Mallory's Triple (MT) stain].

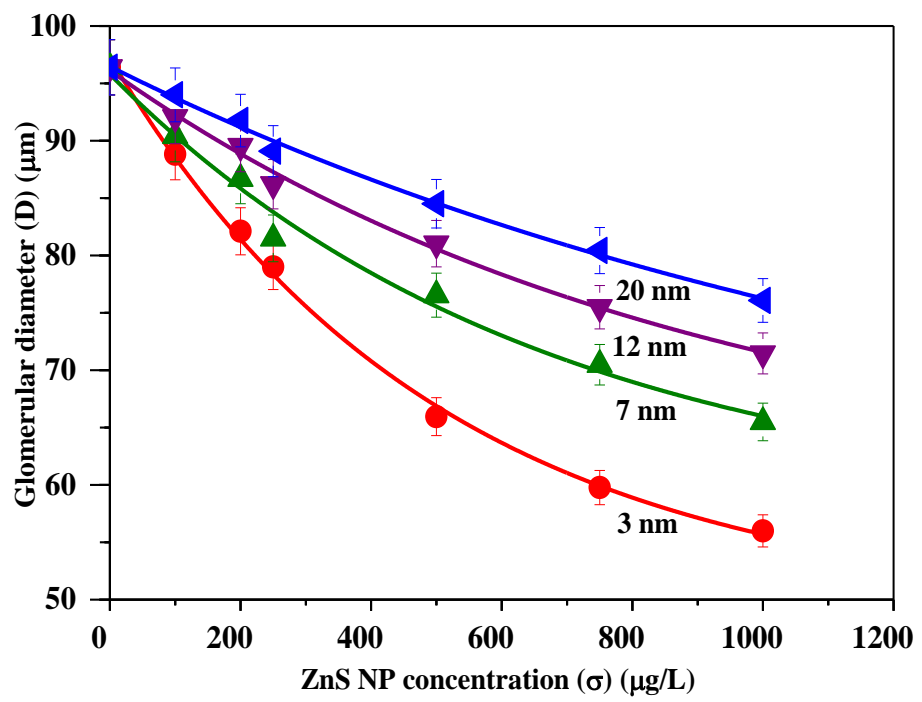

Figure 7:- Variation of the glomerular diameters (D) with increasing nanoparticle concentrations $(\sigma)$ with correspondingly fitted first order exponential decay curves for nanoparticles of different sizes (d) having fixed exposure time (t) of 6 days in L. bata 
Table I:- Fitting parameters for the curves depicting the changes in the values of glomerular diameter (D) with increasing nanoparticle concentration $(\sigma)$ for nanoparticles of different sizes (d) having fixed exposure time of 6 days in L. bata and M. viitatus

\begin{tabular}{|c|c|c|c|c|c|c|}
\hline \multirow{2}{*}{$\begin{array}{c}\text { Nanoparticle } \\
\text { size }(\mathrm{d})(\mathrm{nm})\end{array}$} & \multicolumn{2}{|c|}{$\mathrm{D}(\mu \mathrm{m})$} & \multicolumn{2}{c|}{$\mathrm{A}(\mu \mathrm{m})$} & \multicolumn{2}{c|}{$\mathrm{T}(\mu \mathrm{g} / \mathrm{L})$} \\
\hline & L. bata & M. viitatus & L. bata & M. viitatus & L. bata & M. viitatus \\
\hline 3 & 49.167 & 56.167 & 48.063 & 50.306 & 500.844 & 405.946 \\
\hline 7 & 57.468 & 58.465 & 38.327 & 44.232 & 665.272 & 565.227 \\
\hline 12 & 59.257 & 60.725 & 36.869 & 42.659 & 911.404 & 721.340 \\
\hline 20 & 56.990 & 62.099 & 39.477 & 40.717 & 1393.630 & 1091.433 \\
\hline
\end{tabular}

Impact of ZnS nanoparticle exposure on branchial histology:-

The fish gill is the basic site of respiration, ionic regulation, acid-base regulation, and excretion of nitrogenous wastes [32-34]. Three main cell types are present on the gill surface. The freshwater gill is known to alter its morphology in response to environmental variations, thereby adapting its structure and function to suit its environment [33, 35-38]. Hypoxia is considered as one of the stressors that cause rapid morphological change in fish gills.

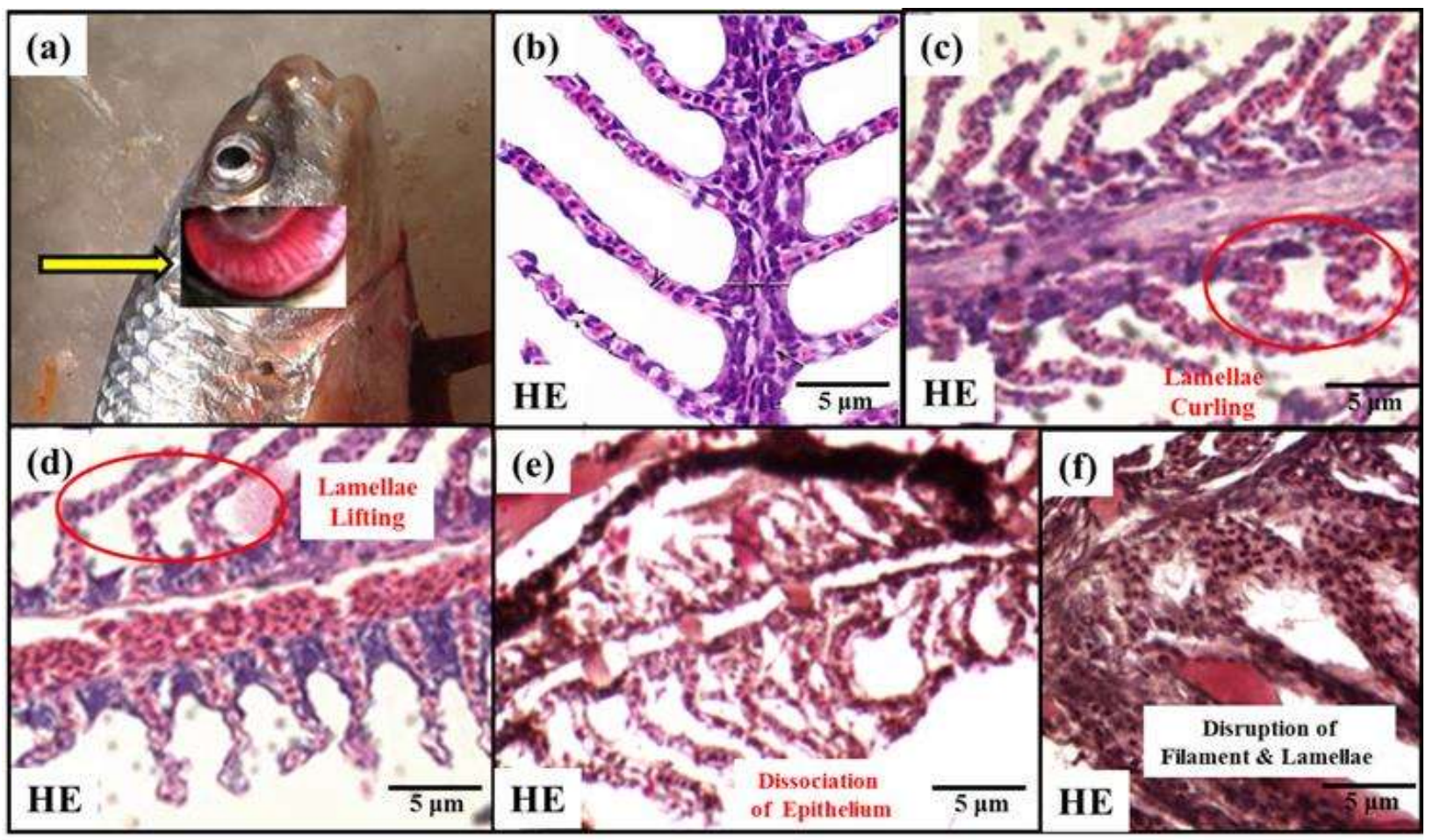

Figure 8:- (a) Position of gills in L. bata; Gill histology of L. bata showing morphological and anatomic changes under exposure of increasing concentration of $\mathrm{ZnS}$ nanoparticles with particle size (d) of $3 \mathrm{~nm}$ : (b) $\sigma=0 \mu \mathrm{g} / \mathrm{L}$, (c) $\sigma$ $=250 \mu \mathrm{g} / \mathrm{L}$, (d) $\sigma=500 \mu \mathrm{g} / \mathrm{L}$ (e) $\sigma=750 \mu \mathrm{g} / \mathrm{L}$ and (f) $\sigma=1000 \mu \mathrm{g} / \mathrm{L}$ for exposure time of $\mathrm{t}=6$ days. [Sections are 3 $\mu \mathrm{m}$ thick and stained with Haematoxilin-Eosin (HE)]

Figure 8 (b)-(f) the branchial histology of $L$. bata in controlled condition and under different experimental conditions while figures 9 (a)-(f) show the same for M. vittatus. From the micrographs it is clear that both the fish species suffer from prominent alterations in their gill histomorphology. For exposure of relatively lower concentration $(\sigma=100 \mu \mathrm{g} / \mathrm{L})$ of $\mathrm{ZnS} \mathrm{NP}$, dissociation of gill epithelium layer is observed in M. vittatus. With increase in $\sigma$ value for fixed NP size $(\mathrm{d}=3 \mathrm{~nm})$ and exposure time $(\mathrm{t}=6$ days), lamellae fusion, lamellae lifting, lamellae curling, vasodilation, angiogenesis are noticed in a dose dependent manner in both the fish species. Finally for $\sigma=1000 \mu \mathrm{g} / \mathrm{L}(\mathrm{d}=3 \mathrm{~nm} ; \mathrm{t}=6$ days $)$ both the fish show disruption of the gill filament and lamellae. Histomorphological changes in fish gills under hypoxia can be attributed to the acclimatization process of the fish to encounter hypoxia by gradual elongation of the respiratory lamellae, expansion of their respiratory surface area and reduction of water-blood diffusion distance. The increase in respiratory surface area and reduction in water-blood diffusion distance should facilitate oxygen uptake during hypoxia. The changes in gill histomorphology occur more 
rapidly in the L. bata but the degree of morphological change of the gills is found to be lower relative to that observed in the M. vittatus. This observation may be a reflection of the more active lifestyle of the M. vittatus.
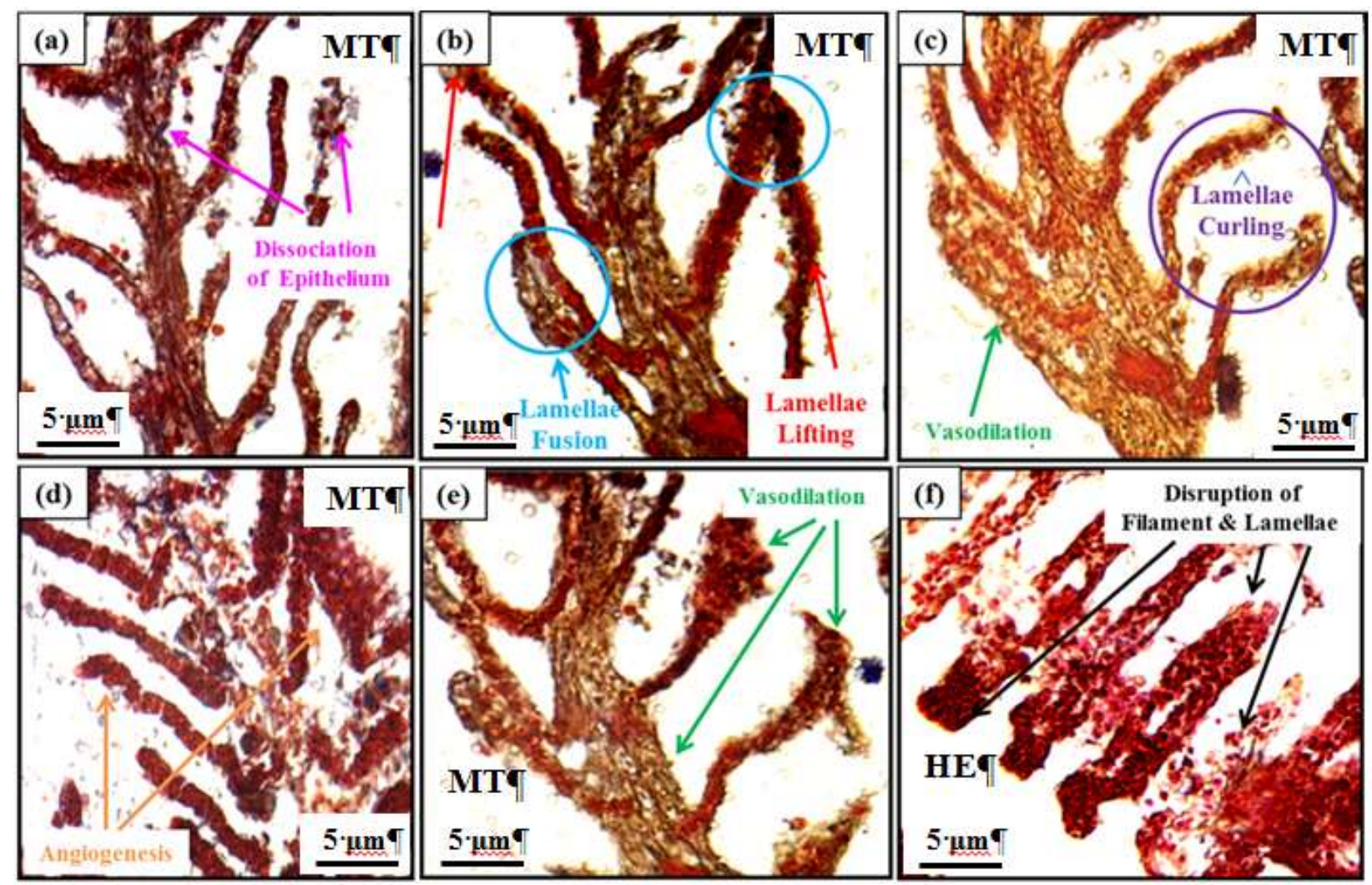

Figure 9:- Gill histology of $M$. vittatus showing morphological and anatomic changes under exposure of increasing concentration of ZnS nanoparticles with particle size (d) of $3 \mathrm{~nm}$ : (a) $\sigma=100 \mu \mathrm{g} / \mathrm{L}$, (b) $\sigma=250 \mu \mathrm{g} / \mathrm{L}$, (c) $\sigma=500$ $\mu \mathrm{g} / \mathrm{L}(\mathrm{d}) \sigma=500 \mu \mathrm{g} / \mathrm{L}$ (e) $\sigma=750 \mu \mathrm{g} / \mathrm{L}$ and (f) $\sigma=1000 \mu \mathrm{g} / \mathrm{L}$ during spawning season. Sections are $3 \mu \mathrm{m}$ thick and stained with Mallory's Triple (MT) and Haematoxilin-Eosin (HE).

\section{Conclusion:-}

Two economically important fish species of different phylogenic group, Labeo bata and Mystus vittatus, has been exposed to ZnS NPs to study and compare the disquieting effect of the NP with respect to some vital organs viz. liver, kidney and gills of the fish. Exposure of $\mathrm{ZnS}$ nanoparticles in water results in significant depletion of dissolved oxygen content associated with reduction in $\mathrm{pH}$ value of water owing to the enhanced photo-oxidation property of the NPs. Both the fish species exposed to $\mathrm{ZnS}$ nanoparticles, responded to hypoxia with varied behavioural, physiological and cellular responses in a dose dependent manner in order to maintain homeostasis and organ function in an oxygen-depleted environment. Experimental observations suggest that the species L. bata is more vulnerable compared to the species $M$. vittatus against $\mathrm{ZnS}$ nanoparticle exposure when vital organs like liver, kidney and gills are concerned. 


\section{References:-}

1. R. J. Aitken, M. Q. Chaudhry, A. B. A. Boxall, M. Hull, Manufacture and use of nanomaterials: current status in the UK and global trends, Occupational Medicine, 56 (2006) 300-306.

2. A. L. Brody, Nano and food packaging technologies converge, Food Technology, 60 (2006) 92-94.

3. B. S. Karnik, S. H. Davies, M. J. Baumann, S. J. Masten, Fabrication of catalytic membranes for the treatment of drinking water using combined ozonation and ultrafiltration, Environmental Science \& Technology, 39 (2005) 7656-7661.

4. C. J. Smith, B. J. Shaw, R. D. Handy, Toxicity of single walled carbon nanotubes to rainbow trout, (Oncorhynchus mykiss): respiratory toxicity, organ pathologies, and other physiological effects, Aquatic Toxicology, 82 (2007) 94-109.

5. E. Oberdörster, Manufactured nanomaterials (fullerenes, $\mathrm{C}_{60}$ ) induce oxidative stress in brain of juvenile largemouth bass, Environmental Health Perspectives, 112 (2004) 1058-1062.

6. J. M. Koziara, P. R. Lockman, D. D. Allen, R. Mumper, In situ blood brain barrier transport of nanoparticles, Journal of Pharmacology Research, 20 (2003) 1772-1778.

7. S. Q. Zhu, E. Oberdörster, M. L. Haasch, Toxicity of an engineered nanoparticle (fullerene, C60) in two aquatic species, Daphnia and fathead minnow, Marine Environmental Research, 62 (2006) S5-S9.

8. B. Bhattacharjee, N. Chatterjee, C. -H. Lu, Harmful Impact of ZnS Nanoparticles on Daphnia sp. in the Western Part (Districts of Bankura and Purulia) of West Bengal, India, ISRN Nanomaterials, doi:10.1155/2013/207239.

9. R. J. Griffitt, R. Weil, K. A. Hyndman, N. D. Denslow, K. Powers, D. Taylor, D. S. Barber, Exposure to Copper Nanoparticles Causes Gill Injury and Acute Lethality in Zebrafish (Danio rerio), Environmental Science \& Technology, 41 (2007) 8178-8186.

10. G. Fedirici, B. J. Shaw, R. D. Handy, Toxicity of titanium dioxide nanoparticles to rainbow trout (Oncorhynchus mykiss): Gill injury, oxidative stress and other physiological effects, Aquatic Toxicology, 84 (2007) 415-430.

11. N. Chatterjee, B. Bhattacharjee, Changing physicochemical properties of water due to exposure of ZnS nanoparticles and its detrimental effect on feeding behaviour and liver of a non-air breathing catfish Mystus vittatus, International Journal of Latest Research in Science and Technology, 3(2014)199-204.

12. N. Chatterjee, B. Bhattacharjee, C.-H. Lu, Hazardous effect of ZnS Nanoparticles on the feeding behaviour, growth and maturation process of the Asian Striped Catfish, Mystus vittatus (Bloch, 1794), International Aquatic Research, 6 (2014) 113-125.

13. P. Domenici, J. F. Steffensen, R. S. Batty, The effect of progressive hypoxia on swimming activity and schooling in Atlantic herring, Journal of Fish Biology, 57 (2000) 1526-1538.

14. D. Dalla Via, G. Van den Thillart, O. Cattani, P. Cortesi, Behavioural responses and biochemical correlates in Solea solea to gradual hypoxic exposure, Canadian Journal of Zoology, 76 (1998) 2108-2113.

15. D. L. Kramer, J. P. Mehegan, Aquatic surface respiration, an adaptive response to hypoxia in the guppy, Poecilia reticulata (Pisces, Poeciliidae), Environmental Biology of Fishes, 6 (1981) 299-313.

16. J. D. Metcalfe, P. J. Butler, Changes in activity and ventilation in response to hypoxia in unrestrained, unoperated dogfish (Scyliorhinus canicula L.), Journal of Experimental Biology, 108 (1984) 414-418.

17. P. Fischer, K. Rademacher, U. Kils, In situ investigations on the respiration and behaviour of the eelpout Zoarces viviparous under short term hypoxia, Marine Ecology Progress Series, 88 (1992) 181- 184.

18. J. K. Carlson, G. R. Parsons, The effects of hypoxia on three sympatric shark species: Physiological and behavioral responses, Environmental Biology of Fishes, 61 (2001) 427-433.

19. J. G. Richards, Metabolic and molecular responses of fish to hypoxia. In Hypoxia, (ed. J. G. Richards, A. P. Farrell, C. J. Brauner), San Diego: Elsevier, 27 (2009) 443-485.

20. N. Chatterjee and B. Bhattacharjee, ZnS nanoparticles affect hazardously the process of oogenesis in the dwarf Asian striped catfish Mystus vittatus (Bloch, 1794), Advanced Science Letters, 22 (1) (2016) 126-131.

21. B. Bhattacharjee and N. Chatterjee, Perilous Effect of ZnS Nanoparticles on Testicular cell development and sperm morphology in the Asian striped catfish Mystus vittatus (Bloch, 1794), Advanced Science Letters, 22 (1) (2016) 64-70.

22. N. Chatterjee and B. Bhattacharjee, Salient alterations in hepatic and renal histomorphology of an Indian minor carp, Labeo bata (Hamilton, 1822) owing to $\mathrm{ZnS}$ nanoparticle induced hypoxia and environmental acidification, The International Journal of Earth \& Environmental Sciences, 1(1) (2015) 1-9.

23. N. Chatterjee and B. Bhattacharjee, An analytic contemplation on the conspicuous vicissitudes in the histomorphology of corpuscles of Stannius of a fresh water catfish Mystus tengara (Hamilton, 1822) due to the exposure of ZnS nanoparticles, Scientifica, 2015 (2015) Article ID 697053, 7 pages. 
24. N. Chatterjee and B. Bhattacharjee, Revelation of $\mathrm{ZnS}$ nanoparticles induce follicular atresia and apoptosis in the ovarian preovulatory follicles in the catfish Mystus tengara (Hamilton, 1822), Scientifica, 2016 (2016) Article ID 3927340, 7 pages.

25. B. Bhattacharjee, N. Chatterjee and C.-H. Lu, Harmful impact of ZnS nanoparticles on Daphnia sp. in the western part (districts of Bankura and Purulia) of West Bengal, India, ISRN Nanomaterials, 2013 (2013) Article ID 207239, 7 pages.

26. H. Segner and H. Möller, Electron microscopical investigations on starvation induced liver pathology in flounders Platichthys flesus, Mar Ecol Prog Ser, 19 (1984)193-196.

27. F. Bagherzadeh Lakani, M. Sattari, I. Sharifpour and R. Kazemi, Effect of hypoxia, normoxia and hyperoxia conditions on gill histopathology in two weight groups of beluga (Huso huso), Caspian J. Env. Sci. 11 (1) (2013) 77-84.

28. T. Wang, S. Lefevre, D. T. T. Huong, N. V. Cong and M. Bayley,. Effects of hypoxia on growth and digestion. In: Richards, J., Brauner, C.J., Farrell, A.P. (Eds.), Fish Physiology, Vol. 27.(2009) Academic Press, San Diego, CA, pp.361-396.

29. S. Rafatnezhad and B. Falahatkar, Nitrogenous compounds and oxygen concentration as the key density dependent factors to optimize growth of beluga, Huso huso (Actinopterygii: Acipenseriformes: Acipenseridae), in circular fiberglass tanks. Acta Ichthyologica. Piscaoriat. 41 (4) (2011) 285-291.

30. K. Pichavant, J. Person-Le-Ruyet, N. Le Bayon, A. Severe, Le A. Roux and G. Boeuf, Comparative effects of long-term hypoxia on growth, feeding and oxygen consumption in juvenile turbot and European sea bass. Journal of Fish Biology, 59 (4) (2001) 875-883.

31. P. Laurent, Gill internal morphology. In Fish physiology. Vol. 10A: Gills. Edited by W.S. Hoar and D.J. Randall. Academic Press, Orlando, Fla. (1984) pp. 73-183.

32. J. M. Wilson and P. Laurent, Fish gill morphology: inside out. J. Exp. Zool. 293(3): (2002) $192-213$. doi:10.1002/jez.10124. PMID: 12115897.

33. D. H. Evans, P. M. Piermarini and K. P. Choe, The multifunctional fish gills: dominant site of gas exchange, osmoregulation, acid-base regulation and excretion of nitrogenous waste. Physiol. Rev. 85(1) (2005) 97-177. doi:10.1152/physrev.00050.2003. PMID: 15618479.

34. P. Laurent, and S. F. Perry,. Environmental effects on fish gill morphology. Physiol. Zool. 64 (1991) 4-25.

35. G. G. Goss, S. F. Perry and P. Laurent, Ultrastructural and morphometric studies on ion and acid-base transport processes in freshwater fish. In Fish physiology. Vol. 14: Cellular and molecular approaches to ionoregulation. Edited by C.M. Wood and T.J. Shuttleworth. Academic Press, New York. (1995) pp. 257-283.

36. M. N. Fernandes and A. F. Mazon, Environmental pollution and fish gill morphology. In Fish adaptation. Edited by A.L. Val and B.G. Kapoor. Enfield Science Publishers, New Dehli and New York. (2003) pp. 203231

37. T. Kaneko, S. Watanabe, and K. M. Lee, Functional morphology of mitochondrion-rich cells in euryhaline and stenohyaline teleosts. Aqua-Biosci. Monogr. 1 (2008) 1-62. doi:10. 5047/absm.2008.00101.0001. 